\title{
Non-operative treatment of thoracolumbar fractures
}

\author{
MB Hartman, AM Chrin and GR Rechtine \\ Florida Orthopaedics, 4175 East Fowler Avenue, Tampa, FL 33617, USA
}

\begin{abstract}
Between 1986 and 1992, 32 thoracolumbar fractures in 32 patients were treated nonoperatively with 4-6 weeks on a rotorest bed followed by bracing with a thoracolumbosacral orthosis for a total of 3-6 months. The fractures were classified as 20 burst, six fracture dislocations, five severe compression fractures, and one gunshot wound. There were 12 multilevel fractures. Nine patients had incomplete neurological injuries and three had complete neurological injuries. The average age was 36.8 years (range 17-63) and the average follow-up was 22.3 months (range 12-60). Fifty three percent $(17 / 32)$ of these had multisystem injuries including visceral trauma and long extremity fractures. There were only two complications; a deep vein thrombosis and a heel ulcer. Neither of these complications extended the patients' hospital stay. All nine of those with incomplete neurological injuries improved at least one Frankel grade. Fifteen of 24 patients who were employed returned to their previous jobs, and only nine patients had persistent back pain requiring medication. Surgical treatment of thoracolumbar fractures is often favored over conservative treatment in the multitrauma and neurologically injured patient because of complications related to bedrest. However, by using a rotorest bed and aggressive physical therapy, conservative treatment may actually result in lower morbidity.
\end{abstract}

Keywords: thoracolumbar fracture; burst fracture; neurological deficits; trauma; conservative treatment

\section{Introduction}

The treatment of thoracolumbar fractures remains a controversial subject. There have been many recent and past reports advocating both operative and nonoperative treatment. ${ }^{1-14}$ There appear to be advantages and disadvantages with each technique. Previous authors have cited re-establishment of spinal anatomy; early mobilization; avoidance of complications secondary to bedrest; and a lower incidence of late deformity with neurological compromise as being reasons for operative treatment. ${ }^{2,3,15-22}$ Special emphasis has been placed on the operative treatment of patients with incomplete neurological compromise. Neurological improvement has been noted to be enhanced with the decompression and stabilization of thoracolumbar fractures. . $^{17,20,23,24}$

Advocates of the non-operative treatment of these injuries believe that acceptable alignment, equivalent neurological recovery, avoidance of late deformity with neurological demise, and a lower complication rate than operatively treated patients can be obtained. $1,4,6,10,25-27$ The goal of our study was to determine if thoracolumbar injuries could be treated safely and effectively using specific non-operative techniques.

Correspondence: Mark B Hartman, Miller Orthopaedic Clinic, Medical Center Plaza, 1001 Blythe Boulevard, Charlotte, NC 28203, USA

\section{Materials and methods}

Between 1986 and 1992, 69 patients with thoracolumbar fractures were treated in Tampa General Hospital. These individuals were given the option of non-operative or operative treatment. Thirty two patients with stable neurological deficits elected for non-operative care, providing our study group of 23 men and 9 women. The average age of the patients was 36.8 years (range 17-63 years). The level of injury ranged from T3 to L5. All fractures were typed according to the Denis Classification System for thoracolumbar injuries. ${ }^{28,29}$ The fractures consisted of 20 burst (14 Denis type B, 4C, 2A), six fracture dislocations, five compression fractures, and one gunshot. Twelve patients had multilevel injuries of which eight were contiguous. The mechanism of injury was a motor vehicle accident in 19 patients, a sports-related injury in seven patients, a fall in five patients, and a gunshot wound in one patient. Seventeen $(53 \%)$ subjects were considered multitrauma patients. The majority of secondary injuries were to the long extremities. Twelve patients had neurological injuries. Nine patients had incomplete neurological deficits and three had complete neurological loss. All patients with neurological injuries were graded using the Frankel Classification System. ${ }^{30}$ Motor and sensory testing were performed by orthopaedic fellows and residents on admission and at subsequent follow-up visits.

Radiographic analysis consisted of anteroposterior and lateral radiographs of the thoracolumbar spine. 
Every patient had a computerized tomographic scan through the injured level. Studies were reviewed for sagittal alignment, vertebral body height, and canal compromise. The subjects' preinjury and postinjury work status were accessed. The patients were also evaluated for residual discomfort and pain medicine usage.

The treatment regimen consisted of 4-6 weeks in a rotorest bed. This period of time was chosen to allow for sufficient healing to avoid progression of vertebral column deformity and pain with mobilization. All patients were managed with aggressive physical therapy and skin care programs. Sequential compression stockings were used for thromboembolic prophylaxis. After the immobilization period was complete, patients were placed in a molded thoracolumbosacral orthosis for 2-3 months.

\section{Results}

The average follow-up was 22.3 months (range 12-60 months) (Table 1). All nine patients with incomplete injuries improved at least one Frankel grade. ${ }^{30}$ Four patients had full neurological recovery. The three patients with complete cord injuries demonstrated no neurological improvement. Fifteen of 24 patients who were working full-time prior to their thoracolumbar fractures returned to their same job. Of the remaining nine, one works full-time light duty, five part-time light duty, and three are medically retired. At the time of this report, nine patients required a non-steroidal anti-inflammatory drug for residual back pain; none of the patients was using narcotics on a regular basis.

Radiographic analysis demonstrated an average (initial injury) kyphosis of $18^{\circ}$ (range $0-30^{\circ}$ ) and vertebral height $65 \%$ of normal (range $40-90 \%$ ). The average canal compromise in the 20 burst fractures and six fracture dislocations was $35 \%$ (range $0-75 \%$ ). Follow-up evaluation of sagittal alignment revealed an average progression of kyphosis by $5.7^{\circ}$ (range $2-30^{\circ}$ ) and the average decrease in vertebral height was $9.7 \%$ (range 7-35\%). Three patients had follow-up computed tomography that demonstrated recanalization of the canal.

Table 1 Patient data

\begin{tabular}{|c|c|c|c|c|c|c|c|c|c|}
\hline \multirow[t]{2}{*}{ Patient } & \multirow{2}{*}{$\begin{array}{l}\text { Age } \\
\text { (yrs) }\end{array}$} & \multirow{2}{*}{$\begin{array}{c}\text { Fracture } \\
\text { type }\end{array}$} & \multirow{2}{*}{$\begin{array}{c}\text { Fracture } \\
\text { level }\end{array}$} & \multirow{2}{*}{$\begin{array}{c}\text { Hospital } \\
\text { stay } \\
\text { (days) }\end{array}$} & \multicolumn{2}{|c|}{ Frankel grade } & \multicolumn{2}{|c|}{ Work status } & \multirow{2}{*}{$\begin{array}{r}\text { Follow-up } \\
\text { (months) }\end{array}$} \\
\hline & & & & & Preop & Postop & Preop & Postop & \\
\hline 1 & 29 & $\mathrm{Fx} /$ disloc & $\mathrm{T} 7$ & 43 & $\mathrm{C}$ & D & FTR & FTR & 10 \\
\hline 2 & 26 & $\mathrm{Fx} /$ disloc & L5 & 60 & $\mathrm{E}$ & $\mathrm{E}$ & FTR & FTR & 48 \\
\hline 3 & 22 & Burst & $\mathrm{T} 12$ & 44 & $\mathrm{D}$ & $\mathrm{E}$ & FTR & LDPT & 25 \\
\hline 4 & 68 & Fx/disloc & T6 & 44 & $\mathrm{E}$ & $\mathrm{E}$ & FTR & FTR & 49 \\
\hline 5 & 61 & Burst & $\mathrm{T} 10$ & 42 & $\mathrm{E}$ & $\mathrm{E}$ & FTR & FTR & 61 \\
\hline 6 & 22 & Burst & L5 & 29 & $\mathrm{E}$ & $\mathrm{E}$ & FTR & FTR & 13 \\
\hline 7 & 27 & Burst & L2 & 46 & $\mathrm{E}$ & $\mathrm{E}$ & FTR & LDPT & 11 \\
\hline 8 & 49 & Burst & $\mathrm{L} 2$ & 29 & $\mathrm{D}$ & $\mathrm{E}$ & FTR & LDPT & 59 \\
\hline 9 & 20 & Fx/disloc & T10 & 145 & $\mathrm{C}$ & $\mathrm{D}$ & STU & STU & 25 \\
\hline 10 & 21 & Compres & $\mathrm{T} 3$ & 40 & $\mathrm{E}$ & $\mathrm{E}$ & FTR & FTR & 10 \\
\hline 11 & 63 & Compres & $\mathrm{T} 10$ & 28 & $\mathrm{E}$ & $\mathrm{E}$ & FTR & FTR & 12 \\
\hline 12 & 22 & Burst & $\mathrm{L} 1$ & 44 & $\mathrm{E}$ & $\mathrm{E}$ & FTR & FTR & 15 \\
\hline 13 & 62 & Compres & $\mathrm{T} 1$ & 52 & $\mathrm{E}$ & $\mathrm{E}$ & MR & MR & 5 \\
\hline 14 & 59 & Fx/disloc & $\mathrm{T} 10$ & 43 & $\mathrm{E}$ & $\mathrm{E}$ & FTR & FTR & 63 \\
\hline 15 & 26 & Burst & $\mathrm{L} 2$ & 40 & $\mathrm{E}$ & $\mathrm{E}$ & FTR & FTR & 7 \\
\hline 16 & 35 & Fx/disloc & $\mathrm{T} 11$ & 39 & $E$ & $\mathrm{E}$ & FTR & FTR & 9 \\
\hline 17 & 31 & Burst & L1 & 42 & $\mathrm{E}$ & $\mathrm{E}$ & FTR & FTR & 23 \\
\hline 18 & 48 & Burst & $\mathrm{L} 2$ & 41 & $\mathrm{C}$ & $\mathrm{D}$ & FTR & LDPT & 27 \\
\hline 19 & 22 & Burst & $\mathrm{T} 12$ & 44 & $\mathrm{E}$ & $\mathrm{E}$ & STU & STU & 11 \\
\hline 20 & 41 & Burst & $\mathrm{T} 4$ & 51 & A & A & FTR & MR & 29 \\
\hline 21 & 48 & Burst & $\mathrm{T} 8$ & 60 & D & $\mathrm{E}$ & FTR & LDPT & 16 \\
\hline 22 & 23 & Burst & $\mathrm{T} 8$ & 49 & $\mathrm{C}$ & $\mathrm{D}$ & UNEMP & MR & 18 \\
\hline 23 & 40 & Burst & L4 & 37 & $\mathrm{E}$ & $E$ & FTR & FTR & 56 \\
\hline 24 & 20 & Burst & L4 & 22 & $\mathrm{E}$ & $\mathrm{E}$ & FTR & FTR & 6 \\
\hline 25 & 64 & Burst & L1 & 40 & $\mathrm{E}$ & $\mathrm{E}$ & FTR & MR & 14 \\
\hline 26 & 38 & Burst & L3 & 24 & $\mathrm{E}$ & $\mathrm{E}$ & FTR & MR & 35 \\
\hline 27 & 17 & Compres & L1 & 50 & $\mathrm{C}$ & $\mathrm{D}$ & STU & STU & 11 \\
\hline 28 & 43 & GSW & $\mathrm{T} 7$ & 35 & $\mathrm{C}$ & $\mathrm{E}$ & UNEMP & UNEMP & 7 \\
\hline 29 & 24 & Burst & L3 & 43 & $\mathrm{E}$ & $E$ & FTR & FTR & 18 \\
\hline 30 & 25 & Burst & T8 & 52 & A & A & FTR & FTL & 15 \\
\hline 31 & 56 & Burst & L1 & 47 & $\mathrm{E}$ & $\mathrm{E}$ & MR & MR & 8 \\
\hline 32 & 19 & $\mathrm{Fx} /$ disloc & $\mathrm{T} 11$ & 35 & A & A & UNEMP & MR & 6 \\
\hline
\end{tabular}

Disloc = dislocations; Compres = compression; GSW = gunshot wound; FTR = full-time regular duty; STU = student; $\mathrm{MR}=$ medically retired; UNEMP = unemployed; FTL = full-time light duty; LDPT = light-duty part time; LDFT = lightduty full time 
There were two complications in our series. One patient had a deep venous thrombosis, and another patient had a superficial heel ulcer. The deep venous thrombosis was treated with anticoagulation and resolved without any residual problems. The heel ulcer was managed with dressing changes and pressure relief; it healed without complications. Neither of these problems lengthened the patients' hospitalization. The average hospital stay was 45 days (range 22-143 days). The long stay of 143 days (one patient) was unrelated to the thoracolumbar fracture.

\section{Discussion}

The conservative treatment of thoracolumbar fractures has come under a great deal of scrutiny. This is especially true in patients with incomplete neurological deficits and multiple injuries. . $^{8,11,18,20}$ Non-operative treatment has traditionally been questioned in these patients. It is believed that anatomical reduction combined with stabilization improves the neurological outcome and lessens both early and late complications when compared to conservative technologies, ${ }^{1,15,17.31}$

More recent literature has demonstrated successful treatment of thoracolumbar fractures with bracing and early mobilization. ${ }^{4,25,26}$ Patients in these studies met certain clinical and radiological criteria including the absence of neurological injury. ${ }^{4}$ It is our contention that the non-operative treatment of patients with thoracolumbar fractures can be used in most patients with results equal or better than is obtained in comparable operative series.

Twelve patients in our series suffered spinal cord injuries secondary to their fractures. All nine patients with incomplete neurological deficits improved at least one Frankel grade and four patients had complete recovery. No patient demonstrated a worsening neurological outcome. The three individuals with complete neurological loss remain unchanged. These results parallel the results of most operative series where canal reconstitution and stabilization were established. . $^{916,20}$ Lemons et $a l^{12}$ found no correlation between canal clearance and neurological recovery in patients with thoracolumbar fractures. This lack of correlation suggests that ongoing neural compression contributes little to overall neurological recovery in the thoracolumbar spine. It is hypothesized that the initial canal encroachment and neurological injury reflects the kinetic energy transferred at the time of injury, thus influencing the prognosis. ${ }^{25}$

There were only two complications in our 32 patients for a rate of $6 \%$. This rate is actually better than the majority of operative series. The complication rates in recent operative series using pedicle fixation studies range from $18 \%$ to $46 \%{ }^{2,3,5}$ The hardware failure rate alone in most pedicle series is higher than our overall complication rate. Infection rates as high as $8 \%$ are reported in some operative series. ${ }^{3}$ The deep venous thrombosis and heel ulcer in our study did not extend the patients' hospital stay or require operative intervention. A large number of complications related to operative treatment of thoracolumbar fractures result in multiple surgical procedures, longer hospital admissions, and enormous hospital costs.

Of the 24 patients who were employed at the time of injury, 21 patients $(88 \%)$ went back to work. Fifteen patients are now working full time regular duty at their previous job. The three patients with complete paraplegia remain unemployed. These results are comparable to operative series. 2.3 .18

Late and chronic back pain has been reported as a problem in the conservatively treated thoracolumbar fractures. ${ }^{18.19 .32}$ Only nine patients required nonsteroidal anti-inflammatory drugs on a daily basis for pain at the time of this report. None of the patients was using narcotics regularly for pain control. No correlation was demonstrated between pain and kyphotic deformity or loss of vertebral height during treatment. This is consistent with the findings of Weinstein et al. ${ }^{27}$

We compared hospital costs of non-operative treatment to two groups of patients treated operatively with pedicle fixation or Harrington instrumentation over the same time period. The non-operative cost averaged $\$ 50,000$ and the pedicle fixation and Harrington instrumentation bills averaged $\$ 40,000$ and $\$ 37,000$, respectively. These prices exclude surgeon fees and costs related to operative complications and hardware removal. When factoring in these parameters, the actual hospital costs incurred were very similar despite the large discrepancy in length of hospitalization between the two groups of patients. The average hospital stay for patients treated operatively in our institution was 25 days compared to 45 days in the non-operative group.

\section{Conclusions}

(1) Aggressive non-operative treatment of patients with thoracolumbar fractures can result in low morbidity and excellent outcome.

(2) Neurological injury and multitrauma are not always contraindications to non-operative treatment.

(3) Non-operative treatment may be medically and economically a more efficient treatment strategy for those with thoracolumbar fractures.

(4) Non-operative treatment is not recommended in patients demonstrating progressive neurological deficits.

\section{References}

1 Bedbrook G. Treatment of thoracolumbar dislocation and fractures with paraplegia. Clin Orthop 1975; 112: 27.

2 Bednar DA. Experience with the 'fixateur interne': initial clinical results. J Spinal Disord 1992; 5: 93.

3 Benson DR et al. Unstable thoracolumbar and lumbar burst fractures treated with the AO fixateur interne. J Spinal Disord 1992; 5: 335-343.

4 Cantor JB, Lebwohl NH, Garvey T, Eismont FJ. Nonoperative management of stable thoracolumbar burst fractures with early ambulation and bracing. Spine 1993; 18: 971.

5 Carl AL, Tromanhauser SG, Roger DJ. Pedicle screw instrumentation for thoracolumbar burst fractures and fracturedislocations. Spine 1992; 17:317.

6 Chan D, Ngian KS, Kaan KT. Nonoperative treatment in burst 
fractures of the lumbar spine (L2-L5) without neurologic deficits. Spine 1992; 17: 317.

7 Davies WE, Morris JH, Hill V. An analysis of conservative (nonsurgical) management of thoracolumbar fracture and fracture dislocation with neural damage. J Bone Joint Surg Am 1980; 62: 7324 .

8 Dickson JH, Harrington PR, Erwin WD. Results of reduction and stabilization of the severely fractured thoracic and lumbar spine. J Bone Joint Surg Am 1978; 60: 799.

9 Esses SI, Botsford DJ, Kostuik JP. Evaluation of surgical treatment for burst fractures. Spine 1990; 15: 667.

10 Gaines RW, Humphreys WG. A plea for judgement in management of thoracolumbar fractures and fracture-dislocations. Clin Orthop 1984; 189.

11 Jacobs RR, Asher MA, Snider RK. Thoracolumbar spinal injuries: A comparative study of recumbent and operative treatment in 100 patients. Spine 1980; 5: 463

12 Lemons VBR, Wagner FC, Montesano PX. Management of thoracolumbar fractures with accompanying neurological injury. Neurosurgery 1992; 30: 667.

13 Lewis J, McKibbin B. The treatment of unstable fracturedislocation of the thoracolumbar spine accompanied by paraplegia. J Bone Joint Surg Br 1974; 56: 603.

14 McEvoy RD, Bradford DS. The management of burst fractures of the thoracic and lumbar spine. Spine 1985; 10: 631.

15 Bohlman $\mathrm{HH}$. Late progressive paralysis and pain following fracture of the thoracolumbar spine. J Bone Joint Surg Am 1976; 58: 728 .

16 Burke DC, Murray DD. The management of thoracic and thoracolumbar injuries of the spine with neurologic involvement. J Bone Joint Surg Br 1976; 58: 72.

17 Clohisy JC et al. Neurologic recovery associated with anterior decompression of spine fractures at the thoracolumbar junction (T12-L1). Spine 1992; 17: 325.

18 Denis F, Armstrong GWD, Searls K, Matta L. Acute thoracolumbar burst fractures in the absence of neurologic deficit: A comparison between operative and nonoperative treatment. Clin Orthop 1984; 189.
19 Denis F, Armstrong WD. Burst fractures in the lumbar spine. Orthop Trans 1981; 5: 417.

20 Kaneda K, Abumi K, Fujiya M. Burst fractures with neurologic deficits of the thoracolumbar lumbar spine. Spine 1984; 9: 788.

21 Lindahl S, Willen J, Irstam L. Unstable thoracolumbar fracture. A comparative radiologic study of conservative treatment and Harrington instrumentation. Acta Radiol Diagn 1984; 26: 67.

22 McNamara MJ, Stephens GC, Spengler DM. Transpedicular short-segment fusions for treatment of lumbar burst fractures. J Spinal Disord 1992; 5: 183.

23 Maiman DJ, Larson SJ, Benzel EC. Neurologic improvement associated with late decompression of the thoracolumbar spine. Neurosurgery 1984; 14: 302.

24 McAfee PC, Bohlman HH, Yuan HA. Anterior decompression of traumatic thoracolumbar fractures with incomplete neurological deficit using tetroperitoneal approach. J Bone Joint Surg Am 1985: 67: 89.

25 Krompinger WJ, Fredrickson BE, Mino DE, Huan HA. Conservative treatment of fractures of the thoracic and lumbar spine. Orthop Clin N Am 1986; 17: 161.

26 Mumford J, Weinstein JN, Spratt KF, Goel GK. Thoracolumbar burst fractures: The clinical efficacy and outcome of non-operative management. Spine 1993; 18: 955.

27 Weinstein JN, Collalto P, Lehmann TR. Thoracolumbar burs fractures treated conservatively: A long-term follow-up. Spine 1988; $13: 33$.

28 Denis F. The three-column spine and its significance in the classification of acute thoracolumbar spinal injuries. Spine 1983; 8: 817 .

29 McAffee PC, Yuan MA, Lasda NA. The unstable burst fracture. Spine 1982; 7: 365.

30 Frankel HL et al. The value of postural reduction in initial management of closed injuries of the spine with paraplegia and tetraplegia. Paraplegia 1969; 7: 179.

31 Malcolm BW, Bradford DS, Winter RA, Chou SN. Posttraumatic kyphosis. J Bone Joint Surg Am 1981; 63: 891.

32 Whitesides TE. Traumatic kyphosis of the thoracolumbar spine. Clin Orthop 1977; 128: 78. 